\title{
Ablation Behavior of a Carbon Fabric Reinforced Phenolic Composite Modified by Surface-Decorated $\mathrm{ZrB}_{2} / \mathrm{SiC}$
}

\author{
Feng $\mathrm{Xu}{ }^{1,2}$, Shizhen Zhu ${ }^{1,2, *}$, Jingdan $\mathrm{Hu}^{1}$, Zhuang Ma ${ }^{1,2}$ and Yanbo Liu ${ }^{1,2}$ \\ 1 School of Material Science and Engineering, Beijing Institute of Technology, Beijing 100081, China; \\ sdxfeng2013@163.com (F.X.); florahjd@163.com (J.H.); hstrong929@bit.edu.cn (Z.M.); \\ boobbyy@163.com (Y.L.) \\ 2 National Key Laboratory of Science and Technology on Material under Shock and Impact, \\ Beijing 100081, China \\ * Correspondence: zhusz@bit.edu.cn; Tel.: +86-010-68911144
}

Received: 2 December 2019; Accepted: 3 January 2020; Published: 7 January 2020

\begin{abstract}
Carbon fabric reinforced phenolic composites were widely used as TPSs (thermal protection system) material in the aerospace industry. However, their limited oxidative ablation resistance restricted their further utility in more serious service conditions. In this study, the surface-decorated $\mathrm{ZrB}_{2} / \mathrm{SiC}$ and its modified carbon fabric reinforced phenolic composites have been successfully prepared. The self-modification mechanism of the surface-decorated $\mathrm{ZrB}_{2} / \mathrm{SiC}$ particles were characterized. The mechanical performance and ablation behavior of the composites were investigated. Results showed that the $\mathrm{ZrB}_{2} / \mathrm{SiC}$ particles possessed a good surface-decorated effect, which achieved good compatibility with the phenolic resin. The mechanical performance of the modified phenolic composite was effectively improved. The anti-oxidative ablation performance of the composite was improved. The mass ablation rate of the surface-decorated $\mathrm{ZrB}_{2}-\mathrm{SiC}$-modified carbon fabric reinforced phenolic composites was $25 \%$ lower than that of the unmodified composites. The formed $\mathrm{ZrO}_{2}$ ceramic layer attached to the surface of the residual chars prevented the heat energy and oxygen from the inner material. Meanwhile, the volatilization of $\mathrm{SiO}_{2}$ and $\mathrm{B}_{2} \mathrm{O}_{3}$ effectively increased the heat dissipation. All these results confirmed that the $\mathrm{ZrB}_{2}-\mathrm{SiC}$ particles can effectively improve the ablation resistance of the composite, which provided a basis for the application of the composites to more serious service environments.
\end{abstract}

Keywords: carbon fabric reinforced phenolic composite; surface-decorated $\mathrm{ZrB}_{2}-\mathrm{SiC}$; mechanical performance; ablation behavior

\section{Introduction}

The serious heating flow formed by the intense friction between a hypersonic vehicle and the surrounding air severely affects the flight stability of an aircraft [1-4]. Carbon fabric reinforced phenolic ( $\mathrm{C}-\mathrm{Ph})$ composites possessing high thermal stability and good mechanical property is an ideal ablative heat-preventing material, which was widely used for thermal protection systems [5-8]. However, with the development of the aerospace industry, the ablation resistance of the C-Ph composite made it difficult to meet the requirements for more serious service conditions. Therefore, using appropriate materials to effectively improve the anti-ablation performance of the $\mathrm{C}-\mathrm{Ph}$ composite is of great significance.

Nowadays, many researches focused on the organic-inorganic hybrid modification using single non-oxide ceramic particles [9-12]. Different kinds of these particles have been used for enhancing the ablation resistance of composites. Ding et al. [10] introduced zirconium silicide into carbon-phenolic 
composites. The $\mathrm{ZrSi}_{2}$ was oxidized to form the $\mathrm{ZrO}_{2}$ and $\mathrm{SiO}_{2}$ during the ablation process, which effectively enhanced the ablation resistance of the $\mathrm{C}-\mathrm{Ph}$ composites. George et al. [11] investigated the thermal stability of $\mathrm{SiC}$-modified phenolic resin composites. They found that $\mathrm{SiC}$ had a positive effect on the matrix phenolic resin, which enhanced the mechanical property and thermo-stability of the composites. Chen et al. [12] studied the ablation mechanism of $\mathrm{ZrB}_{2}$-modified C-Ph composites. They discovered that the existence of $\mathrm{ZrB}_{2}$ remarkably improved the ablation resistance of the $\mathrm{C}-\mathrm{Ph}$ composites due to the formation of $\mathrm{ZrO}_{2}$. Although, all the hybrids exhibited positive characteristics of the added non-oxide ceramic components. It is still difficult to achieve a continuous wide-temperature-range protection during the ablation process.

The multiphase ultra-high temperature ceramic $\mathrm{ZrB}_{2}-\mathrm{SiC}$ was widely used in the field of anti-oxidative ablation for ceramic matrix composites [13-17]. Both $\mathrm{ZrB}_{2}$ and $\mathrm{SiC}$ have special properties in high temperature, such as a great thermal shock resistance, high melting temperature and great chemical inertness. Yang et al. [13] studied the anti-ablation mechanism of the $\mathrm{ZrB}_{2}-\mathrm{SiC}$ coating for $\mathrm{Cf} / \mathrm{SiC}$ composites. They found that the composite possessed better anti-ablative properties. During the ablation process, $\mathrm{ZrB}_{2}-\mathrm{SiC}$ was oxidized to form $\mathrm{B}_{2} \mathrm{O}_{3}, \mathrm{ZrO}_{2}$ and $\mathrm{SiO}_{2}$. The evaporation of $\mathrm{B}_{2} \mathrm{O}_{3}$ and $\mathrm{SiO}_{2}$ can take away a large amount of heat and the melted $\mathrm{SiO}_{2}$ can effectively seal the holes to obstruct the oxygen [14-16]. The formed $\mathrm{B}_{2} \mathrm{O}_{3}, \mathrm{SiO}_{2}$ and $\mathrm{ZrO}_{2}$ can realize continuous wide-temperature-range protection during the ablation process. Therefore, all these indicate that $\mathrm{ZrB}_{2}-\mathrm{SiC}$ is an ideal material to be used for anti-oxidative ablation for resin matrix composites.

In this paper, the $\mathrm{ZrB}_{2}-\mathrm{SiC}$ particles were chemically grafted with 3-aminopropyltriethoxysilane (APS) to have a surface decoration. The purpose of the surface decoration is to achieve the organic-inorganic hybridization of the $\mathrm{ZrB}_{2}-\mathrm{SiC}$ particles and further improve the compatibility between the resin and the particles. Then, different content of surface-decorated $\mathrm{ZrB}_{2}-\mathrm{SiC}$ particles was added to modify the phenolic resin and prepared the composites by compression molding. The self-modification mechanism of the surface-decorated $\mathrm{ZrB}_{2} / \mathrm{SiC}$ particles were investigated. The anti-ablation behavior and mechanism of the composite were analyzed.

\section{Materials and Methods}

\subsection{Materials}

Phenolic resin (solid content of $80 \%$, SW-802) was supplied by the Institute of Chemistry, Chinese Academy of Sciences. Carbon fabric (CF, PAN-based epoxy resin-sized T300, thickness of $0.1 \mathrm{~mm}$ ) was purchased from Xiangsheng CF Technology (Yancheng, Jiangsu) Co., Ltd., China. ZrB $\mathrm{Zn}_{2}$ and $\mathrm{SiC}(1-3 \mu \mathrm{m}, 98 \%$, Forsman Scientific (Beijing) Co., Ltd., China) were used as inorganic additives. 3-aminopropyltriethoxysilane (APS, 99 wt \%) was purchased from Macklin (Beijing) Co., Ltd., China.

\subsection{Preparation of Surface-Decorated $\mathrm{ZrB}_{2}-$ SiC-Modified Phenolic Composites}

Firstly, the $\mathrm{ZrB}_{2}-\mathrm{SiC}$ particles were mixed by mechanical stirring with a volume ratio of 7:3. Then these particles were mixed with absolute ethanol, APS and deionized water according to the ratio as listed in Table 1 . The mixture was heat refluxed at $80^{\circ} \mathrm{C}$ for $10 \mathrm{~h}, 15 \mathrm{~h}$ and $20 \mathrm{~h}$, respectively. Subsequently, the treated particles were washed respectively and dried in an oven at $80^{\circ} \mathrm{C}$ to obtain the surface-decorated $\mathrm{ZrB}_{2}-\mathrm{SiC}$. Next, the surface-decorated $\mathrm{ZrB}_{2}-\mathrm{SiC}$ particles with $20 \mathrm{~h}$ treatment were mixed with the phenolic resin by mechanical stirring for $2 \mathrm{~h}$ according to the mass ratio as shown in Table 1. Finally, the mixture was put into a mold for compression molding to obtain the surface-decorated $\mathrm{ZrB}_{2}-\mathrm{SiC}$-modified phenolic composite. For comparative analysis, an undecorated $\mathrm{ZrB}_{2}$-SiC-modified phenolic composite was also fabricated. The initial size of the sample prepared by compression molding was $100 \mathrm{~mm} \times 100 \mathrm{~mm} \times 10 \mathrm{~mm}$. 
Table 1. The mass proportion of the samples.

\begin{tabular}{cccccc}
\hline Sample & $\mathbf{A P S} / \mathbf{m L}$ & $\mathbf{H}_{\mathbf{2}} \mathbf{O} / \mathbf{m L}$ & Ethanol/mL & $\mathbf{Z r B}_{\mathbf{2}} \mathbf{- S i C} / \mathbf{g}$ & $\mathbf{Z r B}_{\mathbf{2}}-\mathbf{S i C} /$ Phenolic Mass Ratio \\
\hline B1 & 0 & 0 & 0 & 20 & $1: 4$ \\
C1 & 12 & 8 & 80 & 20 & $1: 4$ \\
C2 & 12 & 8 & 80 & 20 & $1: 3$ \\
C3 & 12 & 8 & 80 & 20 & $1: 2$ \\
\hline
\end{tabular}

\subsection{Preparation of Surface-Decorated $\mathrm{ZrB}_{2}-$ SiC-Modified C-Ph Composites}

The surface-decorated $\mathrm{ZrB}_{2}-\mathrm{SiC}$ particles were mixed with the phenolic resin by mechanical stirring for $2 \mathrm{~h}$, according to the mass ratio as listed in Table 2. The $\mathrm{ZrB}_{2}-\mathrm{SiC}$ particles used for the 1B-C-Ph sample were the untreated $\mathrm{ZrB}_{2}-\mathrm{SiC}$ particles. The surface-decorated $\mathrm{ZrB}_{2}-\mathrm{SiC}$ particles used for the 1C-C-Ph and 2C-C-Ph samples were the particles after $20 \mathrm{~h}$ treatment with APS. Subsequently, the carbon fabric was impregnated with the mixture. Then, the prepregs were dried for $6 \mathrm{~h}$ in an oven at $80{ }^{\circ} \mathrm{C}$. Finally, the dried prepregs were cut into pieces of $100 \mathrm{~mm} \times 100 \mathrm{~mm}$ and were stacked up to fabricate in a vulcanizing machine (Huabo Machinery S\&T (Qingdao) Co., Ltd., Qingdao, China) by compression molding. For comparative analysis, the unmodified C-Ph composite was also fabricated. The initial size of the sample prepared by compression molding was $100 \mathrm{~mm} \times 100 \mathrm{~mm} \times 10 \mathrm{~mm}$.

Table 2. The mass proportion of the C-Ph composite samples.

\begin{tabular}{ccc}
\hline Sample & ZrB $_{2}-$ SiC/Phenolic Mass Ratio & Phenolic/Carbon Fabric Volume Ratio \\
\hline Unmodified Composite & 0 & $1: 1$ \\
1B-C-Ph & $1: 4$ & $1: 1$ \\
1C-C-Ph & $1: 4$ & $1: 1$ \\
2C-C-Ph & $1: 3$ & $1: 1$ \\
\hline
\end{tabular}

\subsection{Characterization}

The cross-sectional morphologies of the composites before and after ablation were observed by scanning electron microscopy (SEM, HITACHI S4800, Tokyo, Japan), equipped with an energy-dispersive spectroscope (EDS, HITACHI, Tokyo, Japan). The surface three-dimensional shape of the composite after ablation was obtained by 3D microscope (VHX-2000, KEYENCE, Osaka, Japan). The phase characteristics of the residue were determined by X-ray diffraction (XRD, Karlsruhe, Germany). The molecular structure of the surface-decorated $\mathrm{ZrB}_{2}-\mathrm{SiC}$ was detected by Fourier transform infrared spectroscopy (FTIR, Nicolet, Nexus670, Palo Alto, CA, USA). The mechanical property of the composites was evaluated on a universal testing machine (WD-1, Changchun, China) according to GB/T6569-2006. The size of the sample was $3 \mathrm{~mm} \times 4 \mathrm{~mm} \times 36 \mathrm{~mm}$. The strength could be obtained from the following equation:

$$
\sigma_{f}=\frac{3 F L}{2 b d^{2}}
$$

where $F$ is the maximum compression load at fracture $(\mathrm{N}), b$ and $d$ are the width and thickness $(\mathrm{mm})$ of sample, and $L$ is the span of the clamps. Ablation tests were carried out using an oxyacetylene torch. The test sample of $\Phi 30 \times 10 \mathrm{~mm}$ was subjected to the torch for $30 \mathrm{~s}$. The gas pressures of oxygen and acetylene were $0.7 \mathrm{MPa}$ and $0.05 \mathrm{MPa}$, respectively. The distance from gun to the surface of sample was $25 \mathrm{~mm}$. The mass ablation ratio was calculated by the following formulas:

$$
\operatorname{Mar}=\frac{\Delta m}{\Delta t} .
$$




\section{Results and Discussion}

\subsection{Surface Decoration of $\mathrm{ZrB}_{2}-\mathrm{SiC}$ Particles}

Achieving good surface decoration is the basis for particles possessing good compatibility with the phenolic resin. Figure $1 \mathrm{a}-\mathrm{d}$ shows the micro-morphologies of the $\mathrm{ZrB}{ }_{2}-\mathrm{SiC}$ particles treated with APS after a different treatment time. As shown in Figure 1a, it can be observed that the untreated $\mathrm{ZrB}_{2}-\mathrm{SiC}$ particles exhibited an obvious agglomeration state with a poor dispersion. The small size particles were adsorbed on the surface of the large particles. After surface decoration, the state of the $\mathrm{ZrB}_{2}-\mathrm{SiC}$ particles changed. When the treatment time was up to $20 \mathrm{~h}$, the agglomeration state of the $\mathrm{ZrB}_{2}-\mathrm{SiC}$ particles disappeared. This is because the organic branches on the surface of the $\mathrm{ZrB}_{2}-\mathrm{SiC}$ particles effectively reduced the surface energy and polarity of the powders, which leads to the improvement of the dispersibility of the inorganic particles.
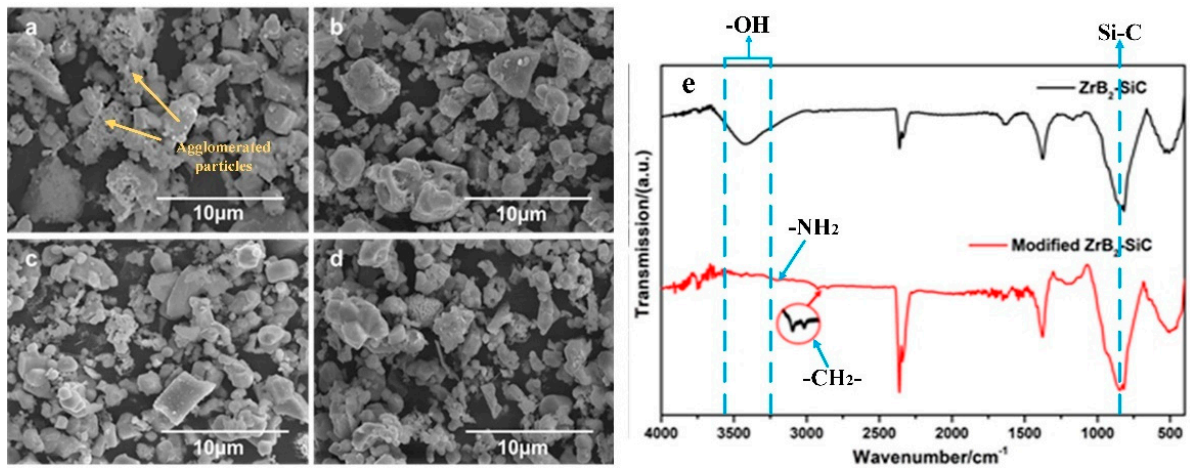

Figure 1. Micro-morphology and FTIR of surface-decorated $\mathrm{ZrB}_{2}-\mathrm{SiC}$ particles treated at different times: (a) Untreated, (b) $10 \mathrm{~h}$, (c) $15 \mathrm{~h}$, (d) $20 \mathrm{~h}$, and (e) FTIR spectrum of the untreated $\mathrm{ZrB}_{2}-\mathrm{SiC}$ particles and the surface-decorated $\mathrm{ZrB}_{2}-\mathrm{SiC}$ particles with $20 \mathrm{~h}$ treatment.

To further analyze the grafting mechanism of surface-decorated $\mathrm{ZrB}_{2}-\mathrm{SiC}$ particles, the molecular structure of the untreated particles and surface-decorated particles after $20 \mathrm{~h}$ treatment were detected by FTIR. As is shown in Figure 1e, all the $\mathrm{ZrB}_{2}-\mathrm{SiC}$ particles before and after surface decoration had absorption peaks at $834 \mathrm{~cm}^{-1}$, which are corresponding to the Si-C bond [18]. Meanwhile, the unmodified particles presented a wide hydroxyl absorption peak. However, after treated with APS for $20 \mathrm{~h}$, the hydroxyl absorption peak disappeared. It indicates that the active groups on the surface of the particles have changed significantly. Additionally, two peaks emerged in the range of 2975-2845 $\mathrm{cm}^{-1}$, corresponding to the vibrating doublet of methylene [19]. Moreover, an absorption peak existed at $3198 \mathrm{~cm}^{-1}$, which was corresponding to the amine group [20]. All these peaks demonstrated the presence of APS organic branches. Therefore, it indicates that the APS has grafted with the hydroxyl groups on the surface of the $\mathrm{ZrB}_{2}-\mathrm{SiC}$ particles. The existence of the organic branches on the surface of the particles provides a prerequisite for achieving good compatibility between the ceramic particles and phenolic resin.

\subsection{Mechanical Property of the Surface-Decorated $\mathrm{ZrB}_{2}-$ SiC-Modified Phenolic Composite}

The mechanical performance of the $\mathrm{ZrB}_{2}-\mathrm{SiC}$-modified phenolic composite reflects the modification effect of the surface-decorated particles on the phenolic resin and directly impacts the stability of the material during ablation process. Therefore, investigating the strength of the modified composite is of great significance. The strength of the composite was characterized by the three-point bending test method; the results are listed in Table 3. It is clear that the untreated $\mathrm{ZrB}_{2}-\mathrm{SiC}$-modified phenolic resin had the lowest strength, which was 69.69 $\mathrm{MPa}$. After being modified with the surface-decorated $\mathrm{ZrB}_{2}-\mathrm{SiC}$ particles, which were treated with APS by $20 \mathrm{~h}$, the strength of the composite was effectively improved. As the content of the particles increased, the bending strength of the material increased 
constantly. When the mass ratio was up to $1: 3$, the composite had the highest strength, up to 89.91 $\mathrm{MPa}$. It indicated that the surface decoration of the particles has a positive influence on the mechanical property of the composite.

Table 3. Bending strength of the $\mathrm{ZrB}_{2}-\mathrm{SiC}$-modified phenolic composites.

\begin{tabular}{ccc}
\hline Sample & $\mathbf{Z r B}_{2}$-SiC/Phenolic Volume Ratio & Bending Strength/MPa \\
\hline B1 & $1: 4$ & $69.69_{-2.5}^{+1.7}$ \\
C1 & $1: 4$ & $77.66_{-1.8}^{+2.4}$ \\
C2 & $1: 3$ & $89.91_{-1.9}^{+2.2}$ \\
C3 & $1: 2$ & $70.36_{-2.4}^{+3.2}$ \\
\hline
\end{tabular}

When the content of surface-decorated $\mathrm{ZrB}_{2}-\mathrm{SiC}$ continuously increased to a mass ratio of 1:2, the bending strength was reduced. To analyze the reason why the mechanical performance of the composite has this change. The micro-morphology of the phenolic composite modified by $\mathrm{ZrB}_{2}-\mathrm{SiC}$ particles before and after surface decoration is shown in Figure 2. As shown in Figure 2a, it was obvious that the untreated $\mathrm{ZrB}_{2}-\mathrm{SiC}$ particles had poor compatibility with the phenolic resin. There were some distinct interface cracks between the particles and the resin. Moreover, some holes existed in the resin. During the bending test process, these defect areas became the stress concentration area, which directly led to the fracture failure of the material. The surface-decorated $\mathrm{ZrB}_{2}-\mathrm{SiC}$-modified phenolic composite was shown in Figure $2 b, c$, the particles dispersed in the phenolic resin uniformly and the composite formed a dense structure. There were no obvious defects, such as cracks or holes in the interiors of composites. Furthermore, the existence of flexible groups, which comes from the silane coupling agent, could facilitate the absorption of the impact energy and improve the bonding strength of the composite. Meanwhile, after surface decoration by APS, the resin and the surface-decorated particles formed a chemical bond due to the newly created functional groups [21]. All these lead to the improvement of bending strength. However, when the mass ratio reached 1:2, the formability of the composite decreased obviously. Some distinct internal defects appeared, and the composite possessed a non-uniform structure with a large number of holes as illustrated in Figure $2 \mathrm{~d}$. This is mainly because that the presence of large amounts of inorganic particles blocking the cross-linking movement of the phenolic molecular during the curing process, which affected the formation of resin. Moreover, the increased viscosity of the mixture decreased the dispersion degree of the particles, which led to the formation of internal defects. Therefore, the bending strength was reduced.
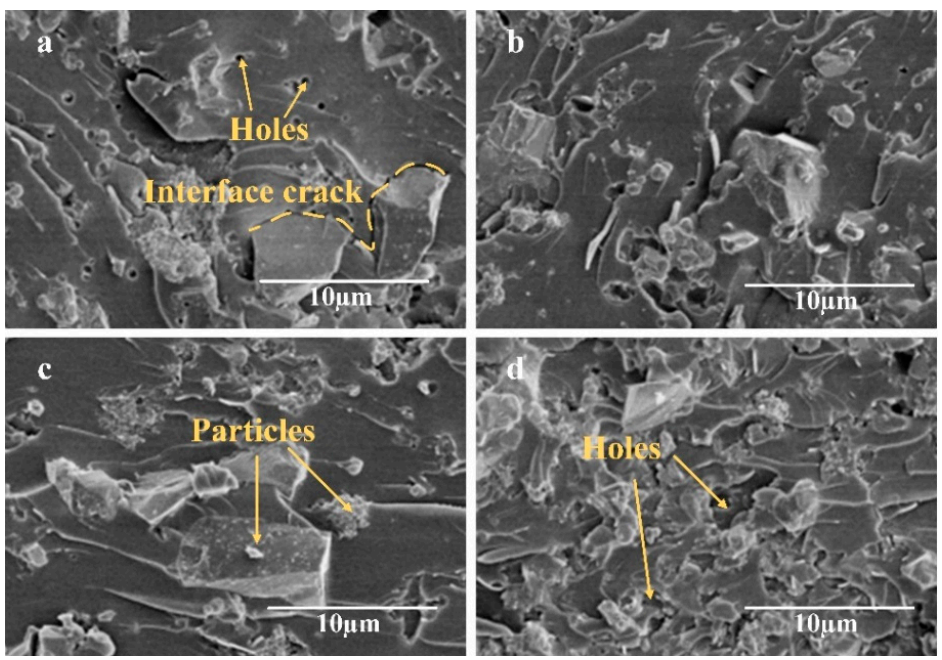

Figure 2. Micro-morphology of $\mathrm{ZrB}_{2}-\mathrm{SiC}$-modified phenolic composite: (a) Unmodified ZrB2-SiC-modified phenolic composite, (b) C1 sample, (c) C2 sample, and (d) C3 sample. 


\subsection{Ablation Behavior of the Surface-Decorated $\mathrm{ZrB}_{2}-$ SiC-Modified C-Ph Composite}

Oxyacetylene torch ablation test was carried out to test the ablation behavior of the C-Ph composite. The mass ablation ratio of four composites is listed in Table 4. We can observe that the unmodified $\mathrm{C}-\mathrm{Ph}$ had the highest mass ablation ratio, up to $4.61 \times 10^{-2} \mathrm{~g} \cdot \mathrm{s}^{-1}$. It suggests that the unmodified C-Ph composite had a high ablation degree. However, after modification with $\mathrm{ZrB}_{2}-\mathrm{SiC}$, the mass ablation ratio was reduced. Moreover, with the same content of surface-decorated $\mathrm{ZrB}_{2}-\mathrm{SiC}$, the mass ablation ratio of the $1 \mathrm{C}-\mathrm{C}-\mathrm{Ph}$ composite was similar to that of the $1 \mathrm{~B}-\mathrm{C}-\mathrm{Ph}$ composite. It suggests that the surface decoration of the particle has little influence on the ablation resistance of the composite. When the content of the surface-decorated $\mathrm{ZrB}_{2}-\mathrm{SiC}$ was $25 \mathrm{wt} \%$, the ratio was reduced by $25 \%$ compared with that of the unmodified $\mathrm{C}-\mathrm{Ph}$ composite. This demonstrates that the addition of $\mathrm{ZrB}_{2}-\mathrm{SiC}_{\text {particles }}$ itself effectively improved the oxidation ablation performance of the composite.

Table 4. Mass ablation ratio of the modified $\mathrm{C}-\mathrm{Ph}$ composites.

\begin{tabular}{cc}
\hline Sample & Mass Ablation Ratio/(10 $\left.\mathbf{- 2} \mathbf{g} \cdot \mathbf{s}^{\mathbf{- 1}}\right)$ \\
\hline Unmodified Composite & 4.61 \\
1B-C-Ph & 3.88 \\
1C-C-Ph & 3.87 \\
2C-C-Ph & 3.46 \\
\hline
\end{tabular}

To further analyze the ablation behavior of the composite, the unmodified composite and 2C-C-Ph composite were chosen to characterize the macro ablation response. The ablated morphology of these two composites is shown in Figure 3. The unmodified sample exhibited an obvious ablation morphology as illustrated in Figure 3a. The carbon fabric was exposed, and a distinct ablation pits appeared on the central surface of the composite. Moreover, due to the serious oxidative and mechanical erosion resulted from the combustion, the depth of the ablation pit was up to $3.015 \mathrm{~mm}$. However, with the modification of the surfaced-decorated $\mathrm{ZrB}_{2}-\mathrm{SiC}$ particles, the ablation morphology of the composite changed. There was a large amount of white accumulations that covered the ablated surface, as shown in Figure 3c. With the protection of these white accumulations, the depth of the ablation pit was reduced. All these indicate that the presence of the surfaced-decorated $\mathrm{ZrB}_{2}-\mathrm{SiC}_{\mathrm{C}}$ particles changes the ablation behavior of the composite.
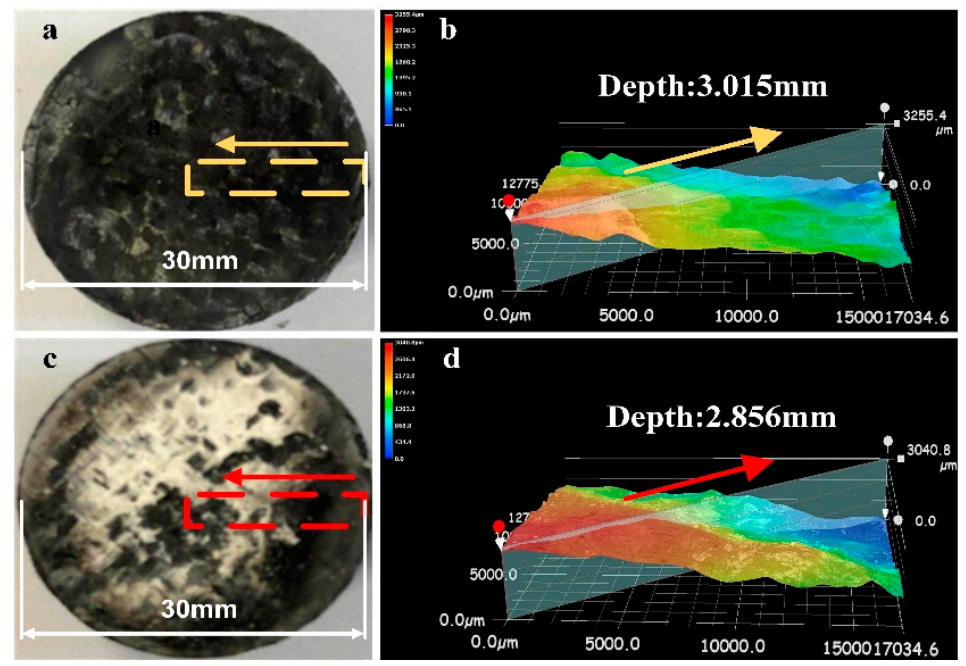

Figure 3. Ablation morphology of the composite: (a) Unmodified composite, (b) 3D image of the unmodified composite, (c) the 2C-C-Ph composite, and (d) 3D image of the 2C-C-Ph composite.

XRD was used to analyze the phase compositions of the residue on the surface of the composite. The X-ray diffraction patterns are shown in Figure 4. The top curve is the pattern of the unmodified 
composite. Two broad peaks appeared at nearly $23^{\circ}$ and $44^{\circ}$, corresponding to the (002) and (100) lattice planes of graphite, respectively [22,23]. It indicates that the residual char underwent a certain degree of graphitization transformation at high temperature [24]. As for the middle curve related to the 2C-C-Ph composite, the pattern incurred an obvious change, whereby the broad peaks disappeared and were replaced by the characteristic peaks of $\mathrm{m}-\mathrm{ZrO}_{2}$. Moreover, there was also some characteristic peaks of $\mathrm{ZrB}_{2}$. All these suggest that the main phase composition of the white accumulations is $\mathrm{m}-\mathrm{ZrO} \mathrm{r}_{2}$ while some unoxidized $\mathrm{ZrB}_{2}$ remained. We can conclude that $\mathrm{ZrB}_{2}$ is continuously oxidized to supply the zirconia during the ablation, which effectively avoids the loss of $\mathrm{ZrO}_{2}$ caused by mechanical erosion. However, as we all know, the oxidation products of $\mathrm{ZrB}_{2}-\mathrm{SiC}$ were $\mathrm{ZrO}_{2}, \mathrm{SiO}_{2}$ and $\mathrm{B}_{2} \mathrm{O}_{3}$. Within the ultrahigh ablation temperature, the $\mathrm{B}_{2} \mathrm{O}_{3}$ incurred serious volatilization. Meanwhile, $\mathrm{SiO}_{2}$ was melted and volatilized and some remains existed in the form of a glass phase. Therefore, it cannot be detected by the XRD.

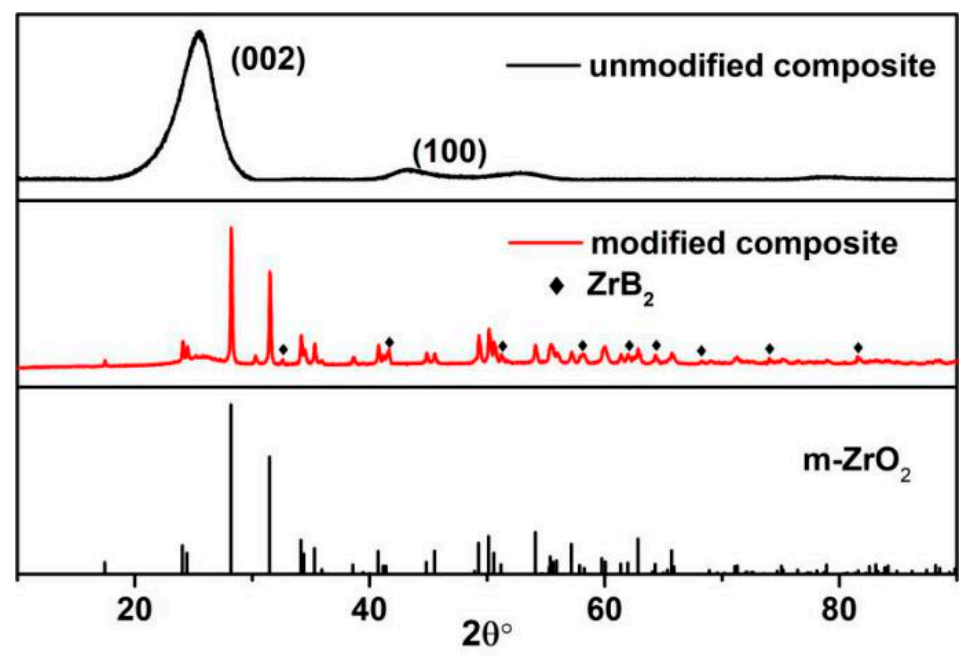

Figure 4. XRD pattern of the composite after ablation.

\subsection{Ablation Mechanism of the Surface-Decorated $\mathrm{ZrB}{ }_{2}-$ SiC-Modified C-Ph Composite}

The micro-morphology of the composites after ablation is shown in Figure 5. Figure 5a shows the morphology of unmodified composite, and we can observe that the reinforced carbon fabric was retained on the surface of the composite with a staggered arrangement. Due to the mechanical and oxidative erosion of the flame flow, the surface residual chars almost disappeared. Moreover, the carbon fiber bundles were separated, which led to the inner matrix resin being directly exposed to the flame flow. Therefore, some residual chars pyrolyzed from the inner resin was interposed between the carbon fibers. From the magnification image as shown in Figure 5a, the carbon fiber showed an obvious oxidative morphology with a needle-like structure. It indicates that, during the ablation process, the composites underwent a severe oxidative ablation and mechanical erosion caused by the flame.

After modified with the surface-decorated $\mathrm{ZrB}_{2}-\mathrm{SiC}$ particles, the micro-morphology was changed. As shown in Figure 5b,c, an obvious ceramic layer covered the surface of the ablated region. Under the ceramic layer, the residual char existed with a three-dimensional network structure. Although, parts of the surface ceramic accumulations were peeled off; the retained ceramic layer effectively decreased the mechanical and oxidative erosion on the inner material. Moreover, the porous structure of the residual char formed by the evaporation of the pyrolysis gas, such as $\mathrm{H}_{2} \mathrm{O}, \mathrm{CO}, \mathrm{CO}_{2}$ and $\mathrm{CH}_{4}$, acted as a poor thermal conductor, which effectively obstructed the heat transmission. From the magnification image of the ceramic layer, we can observe that the accumulations possessed an obvious sintered morphology. Combined with the XRD results, we can conclude that the $\mathrm{m}-\mathrm{ZrO}_{2}$ has incurred sintering to form a dense ceramic layer. However, some holes also existed in the ceramic layer, which resulted from 
the volatilization of $\mathrm{B}_{2} \mathrm{O}_{3}$ and silica. Moreover, the volatilization of the low melting point oxides can effectively enhance the heat dissipation during the ablation process. Therefore, all these indicate that the addition of the $\mathrm{ZrB}_{2}-\mathrm{SiC}$ particles can improve the ablation resistance of the composite.
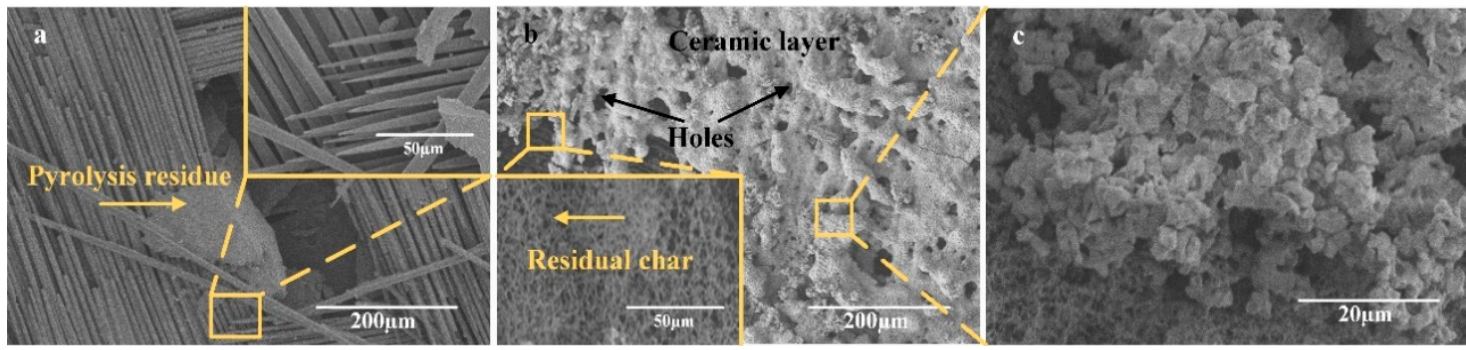

Figure 5. Micro-morphology of composites after ablation: (a) Unmodified composite, (b) 2C-C-Ph composite, and (c) magnification image of the ceramic layer of the $2 \mathrm{C}-\mathrm{C}-\mathrm{Ph}$ composite.

From the above analysis, we can conclude that the ablation behavior of the modified composite has changed significantly. To deeply analyze the anti-ablation mechanism of the modified composite, a detailed analysis of the composite ablated surface was made. Figure 6 shows the micro-morphology of the area without ceramic accumulations and the edge area of the ceramic accumulations. As shown in Figure $6 \mathrm{a}$, in the area where the surface ceramic layer was eroded by the flame flow, the carbon fabrics was exposed with a little ceramic accumulations and residual chars. What was different with the unmodified composite, these carbon fibers still possessed good arrangement and the bundles were tight. It suggests that the ceramic layer can effectively decrease the surface erosion degree of the composite. At the edge area, we can observe that the thickness of the accumulations gradually decreased. Through the EDS analysis, the ceramic accumulations were composed with $\mathrm{O}$ and $\mathrm{Zr}$. It suggests that there is no silicon presented on the surface of the ceramic accumulations. Combined with the XRD analysis, it can be proved that the accumulations were $\mathrm{m}-\mathrm{ZrO}_{2}$. In the bare fiber area, there were many melted particles that were interposed between the carbon fibers. Moreover, from the magnification image as shown in Figure 6c, no obvious oxidative morphology existed on the surface of the carbon fabrics. Some melted ceramic accumulations covered on the surface of the fibers, which effectively provided an effective protection for the carbon fibers. Therefore, we can conclude that the formed ceramic layer plays an essential role on the anti-oxidative ablation performance of the composite.
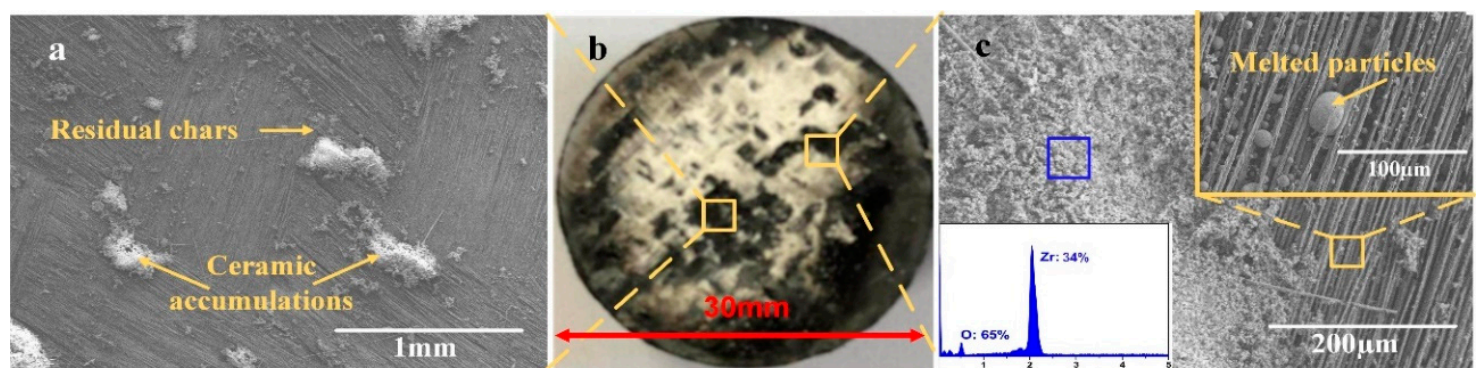

Figure 6. The ablated morphology of the 2C-C-Ph composite at different region: (a) The area without ceramic accumulations, (b) the 2C-C-Ph composite, and (c) the edge area of ceramic accumulations.

To further reveal the anti-ablation mechanism of the surface-decorated $\mathrm{ZrB}_{2}-\mathrm{SiC}$-modified composite, a diagram model was established on the basis of the above analysis. As shown in Figure 7 , in the initial stage of ablation, the flame flow directly led to the pyrolysis of the matrix resin and oxidation of the inorganic particles. With the deposition of heat energy, the oxidative products, such as $\mathrm{B}_{2} \mathrm{O}_{3}$ and $\mathrm{SiO}_{2}$, were melted and volatilized. Combined with the pyrolysis gas formed by the matrix resin, it can effectively improve the heat dissipation. Moreover, due to the serious 
mechanical and oxidative erosion of the flame flow, the residual chars and ceramic accumulations were eroded. As the ablation time increase, the ablation degree was enhanced. The ceramic accumulations were continuously generated and sintered, which covered the surface of the composite. With the volatilization of the $\mathrm{B}_{2} \mathrm{O}_{3}$ and $\mathrm{SiO}_{2}$, the main composition of the ceramics was $\mathrm{m}-\mathrm{ZrO}_{2}$. Because the oxygen diffusion index of $\mathrm{m}-\mathrm{ZrO}_{2}$ is $10^{-9} \mathrm{~g} / \mathrm{cm} \cdot \mathrm{s}$ [25], it can act as a good oxygen barrier to prevent the oxidative flame from the inner material. Meanwhile, with the protection of the ceramic layer, the inner residual chars were retained, which can act as a thermal insulator and effectively obstruct the heat transmission [26]. However, some ceramic accumulations and residual chars were eroded by the mechanical erosion of the flow, and the inner carbon fabrics was exposed to the flame. Meanwhile, with the coverage of the ceramics, the carbon fabrics still kept their arrangement without oxidative ablation. Therefore, the $\mathrm{ZrB}_{2}-\mathrm{SiC}$-modified $\mathrm{C}$-Ph composite has a good anti-ablation performance.

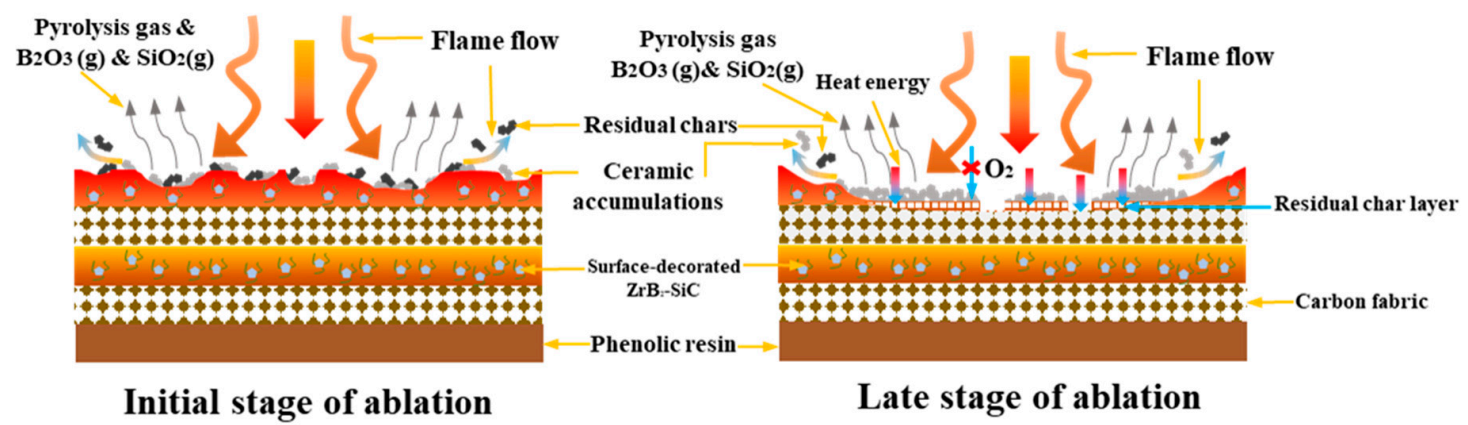

Figure 7. Diagram of the underlying ablation resistance mechanism of surface-decorated $\mathrm{ZrB}_{2}-\mathrm{SiC}$-modified composites.

\section{Conclusions}

Surface-decorated $\mathrm{ZrB}_{2}-\mathrm{SiC}$-modified phenolic composites and carbon fabric reinforced phenolic composites were fabricated by thermal compression molding. The mechanical property and ablation resistance of the composites were characterized. It was observed that the organic branches were effectively retained on the surface of the particles with the treatment of APS for $20 \mathrm{~h}$. The agglomeration degree of the particles was reduced and the dispersibility of particles in the phenolic resin was improved. The organic branches of the surface-decorated $\mathrm{ZrB}_{2}-\mathrm{SiC}$ enhanced the interface performance between the resin and particles. The mechanical property of the surface-decorated $\mathrm{ZrB}_{2}-\mathrm{SiC}$-modified phenolic composites was enhanced by $13 \%$, compared with the same content $\mathrm{ZrB}_{2}-\mathrm{SiC}$-modified phenolic composite. Moreover, the surface decoration has no significant effect on the ablation resistance of composites. The existence of the $\mathrm{ZrB}_{2}-\mathrm{SiC}$ particles improved the ablation resistance of the $\mathrm{C}-\mathrm{Ph}$ composite. The mass ablation ratio was reduced by $25 \%$, compared with the unmodified $\mathrm{C}-\mathrm{Ph}$ composite. The formed $\mathrm{ZrO}_{2}$ layer covered the surface of the composite, effectively preventing the heat and oxygen from penetrating into the interior. Meanwhile, the volatilization of the molten $\mathrm{SiO}_{2}$ and $\mathrm{B}_{2} \mathrm{O}_{3}$ combined with the pyrolysis gas effectively dissipated the heat energy and further improved the ablation resistance of the composite. Thus, the surface-decorated $\mathrm{ZrB}_{2}-\mathrm{SiC}$ can effectively improve the interface properties between particles and phenolic resin and the particles itself can effectively enhance the anti-oxidative ablation performance of the composite.

Author Contributions: Experiment and manuscript writing, F.X. and J.H.; Supervision and experimental guidance, S.Z. and Y.L.; Experimental guidance, Z.M. All authors have read and agreed to the published version of the manuscript.

Funding: This research was funded by National Natural Science Foundation of China (51772027).

Conflicts of Interest: The authors declare that they have no known competing financial interest or personal relationship that could have appeared to influence the work reported in this paper. 


\section{References}

1. Tang, S.F.; Hu, C.L. Design, Preparation and Properties of Carbon Fiber Reinforced Ultra-High Temperature Ceramic Composites for Aerospace Applications: A Review. J. Mater. Sci. Technol. 2017, 33, 117-130. [CrossRef]

2. Natali, M.; Kenny, J.M.; Torre, L. Science and technology of polymeric ablative materials for thermal protection systems and propulsion devices: A review. Prog. Mater. Sci. 2016, 84, 192-275. [CrossRef]

3. Ma, Y.Y.; Yang, Y.; Lu, C.X.; Wen, X.; Liu, X.; Lu, K.; Wu, S.; Liu, Q. Extraordinary improvement of ablation resistance of carbon/phenolic composites reinforced with low loading of graphene oxide. Compos. Sci. Technol. 2018, 167, 53-61. [CrossRef]

4. Rivier, M.; Lachaud, J.; Congedo, P.M. Ablative thermal protection system under uncertainties including pyrolysis gas composition. Aerosp. Sci. Technol. 2019, 84, 1059-1069. [CrossRef]

5. Park, J.K.; Cho, D.; Kang, T.J. Acomparison of the interfacial, thermal and ablative properties between spun and filament yarn type carbon fabric/phenolic composites. Carbon 2004, 42, 795-804. [CrossRef]

6. Amirsardari, Z.; Aghdam, R.M.; Niasari, M.S.; Jahannama, M.R. Influence of $\mathrm{ZrB}_{2}$ Nanoparticles on the Mechanical and Thermal Behaviors of Carbon Nanotube Reinforced Resol Composite. J. Mater. Sci. Technol. 2016, 32, 611-616. [CrossRef]

7. Srikanth, I.; Padmavathi, N.; Kumar, S.; Ghosal, P.; Kumar, A.; Subrahmanyam, C. Mechanical, thermal and ablative properties of zirconia, CNT modified carbon/phenolic composites. Compos. Sci. Technol. 2013, 80, 1-7. [CrossRef]

8. Eslami, Z.; Yazdani, F.; Mirzapour, M.A. Thermal and mechanical properties of phenolic-based composites reinforced by carbon fibers and multiwall carbon nanotubes. Compos. Part. A-Appl. Sci. Manuf. 2015, 72, 22-31. [CrossRef]

9. Ma, C.; Ma, Z.; Gao, L.H.; Wu, T.; Wang, F.; Ishida, H. Zirconium carbide-modified polymer-matrix composites with improved reflectivity under high-energy laser ablation. Ceram. Int. 2019, 45, 17681-17687. [CrossRef]

10. Ding, J.; Huang, Z.; Qin, Y.; Shi, M.; Huang, C.; Mao, J. Improved ablation resistance of carbon-phenolic composites by introducing zirconium silicide particles. Compos. B Eng. 2015, 82, 100-107. [CrossRef]

11. George, P.; Cristina, E.P.; Adriana, S.; Dincă, I.; Ficai, A.; Andronescu, E.; Truşcă, R. Influence of nanometric silicon carbide on phenolic resin composites properties. Bull. Mater. Sci. 2016, 39, 769-775.

12. Chen, X.Y.; Chen, P.; Hong, C.Q. Improved ablation resistance of carbon-phenolic composites by introducing zirconium diboride particles. Compos. B Eng. 2013, 47, 320-325. [CrossRef]

13. Huang, D.; Zhang, M.Y.; Huang, Q.Z.; Wang, L.; Tong, K. Mechanical Property, Oxidation and Ablation Resistance of $\mathrm{C} / \mathrm{C}-\mathrm{ZrB}_{2}-\mathrm{ZrC}-\mathrm{SiC}$ Composite Fabricated by Polymer Infiltration and Pyrolysis with Preform of $\mathrm{C}_{\mathrm{f}} / \mathrm{ZrB}_{2}$. J. Mater. Sci. Technol. 2016, 33, 481-486. [CrossRef]

14. Zhang, D.Y.; Hu, P.; Dong, S. Oxidation behavior and ablation mechanism of Cf $/ \mathrm{ZrB}_{2}-\mathrm{SiC}$ composite fabricated by vibration-assisted slurry impregnation combined with low-temperature hot pressing. Corros. Sci. 2019, 161, 108181. [CrossRef]

15. Aliasgarian, R.; Seyyed, M.N.; Mirsalehi, E. Ablation mechanism of $\mathrm{ZrB}_{2}-\mathrm{SiC}$ coating for SiC-coated graphite under an oxyacetylene flame. Surf. Coat. Technol. 2018, 350, 511-518. [CrossRef]

16. Zhao, X.; Wang, Y.G.; Duan, L.Y. Improved ablation resistance of $\mathrm{C} / \mathrm{SiC}-\mathrm{ZrB} \mathrm{r}_{2}$ composites via polymer precursor impregnation and pyrolysis. Ceram. Int. 2017, 43, 12480-12489. [CrossRef]

17. Xu, Y.L.; Sun, W.; Xiong, X. Ablation characteristics of mosaic structure ZrC-SiC coatings on low-density, porous C/C composites. J. Mater. Sci. Technol. 2019, 35, 2785-2798. [CrossRef]

18. Xia, X.; Jiang, W.H.; Chen, T.; Liu, J.; Miao, L.; Zhang, X. Preparation of C@ZrSiO4 Inclusion Pigment using Compound Colorants via Non-hydrolytic Sol-gel Method. Adv. Mater. 2014, 936, 170-175.

19. Xie, D.J.; Xu, J.; Cheng, H.F.; Wang, N.; Zhou, Q. The role played by amine and ethyl group in the reversible thermochromic process of $\left[\left(\mathrm{C}_{2} \mathrm{H}_{5}\right)_{2} \mathrm{NH}_{2}\right]_{2} \mathrm{CuCl}_{4}$ probing by FTIR and 2D-COS analysis. J. Mol. Struct. 2018, 1161, 267-272. [CrossRef]

20. Ovchinnikov, O.V.; Evtukhova, A.V.; Kondratenko, T.S.; Smirnov, M.S.; Khokhlov, V.Y.; Erina, O.V. Manifestation of intermolecular interactions in FTIR spectra of methylene blue molecules. Vib. Spectrosc. 2016, 86, 181-189. [CrossRef]

21. Yuan, H.; Wang, C.G.; Zhang, S. Effect of surface modification on carbon fiber and its reinforced phenolic matrix composite. Appl. Surf. Sci. 2012, 259, 288-293. [CrossRef] 
22. Ma, C.; Ma, Z.; Gao, L.H.; Liu, Y.; Wu, T.; Wang, F.; Ishida, H. Ablation behavior of boron-modified phenolic resin irradiated by high-energy continuous-wave laser and its evolution of carbon structure. Mater. Des. 2019, 180, 107954. [CrossRef]

23. Xu, F.; Zhu, S.Z.; Ma, Z.; Li, H.; Wang, J.; Wu, T.; Wang, F. Ablation behavior of inorganic particle-filled polybenzoxazine composite coating irradiated by high-intensity continuous laser. Ceram. Int. 2019, 45, 14968-14975. [CrossRef]

24. Zhao, M.; Song, H.H. Catalytic Graphitization of Phenolic Resin. J. Mater. Sci. Technol. 2011, 27, $266-270$. [CrossRef]

25. Han, J.C.; He, X.D.; Du, S.Y. Oxidation and ablation of 3D carbon-carbon composite at up to $3000{ }^{\circ} \mathrm{C}$. Carbon 1995, 33, 473-478. [CrossRef]

26. Cheon, J.H.; Shin, E.S. Assessment of the ablation characteristics of carbon/phenolic composites using X-ray microtomography. Compos. Sci. Technol. 2019, 182, 107740. [CrossRef]

(C) 2020 by the authors. Licensee MDPI, Basel, Switzerland. This article is an open access article distributed under the terms and conditions of the Creative Commons Attribution (CC BY) license (http://creativecommons.org/licenses/by/4.0/). 